\title{
Enzyme Concentration, Substrate Concentration and Temperature Based Formulas for Obtaining Intermediate Values of the Rate of Enzymatic Reaction Using Lagrangian Polynomial
}

\author{
Nizam Uddin \\ M. B. Khalsa College, Indore (M.P.), India. \\ E-mail: nizamuddin4research@ gmail.com
}

\begin{abstract}
This research paper is based on obtaining intermediate values of the rate of Enzymatic reaction. The Rate of Enzymatic reaction is affected by concentration of substrate, Temperature, concentration of enzyme and other factors. Take some mathematical functions which are defined the rate of enzymatic reaction in interval. Functions are followed " $n$ " limit which is optimum limit and other factors are to be constant in each function. And apply Lagrangian polynomial on the functions.
\end{abstract}

Kevwords: Concentration of enzyme, Concentration of substrate, Lagrangian polynomial, Rate of Enzymatic reaction, Temperature.

\section{Introduction}

Lagrangian polynomial is used for polynomial interpolation. For a given set of distinct points $x_{j}$ and numbers $y_{\mathbf{j}}$, the Lagrange polynomial is the polynomial of the least degree that at each point $\mathrm{x}_{\mathrm{j}}$ assumes the corresponding value $\mathrm{y}_{\mathrm{j}}$ [1]. The Rate of Enzymatic reaction (V) is affected by concentration of substrate (S), Temperature $(\mathrm{T})$, concentration of enzyme $(\mathrm{E})$. Increasing their values are increase the rate of Enzymatic reaction (V) [2,3]. Their interval values are followed the functions: 


$$
\begin{aligned}
& V=f(T) \\
& V=f(S) \\
& V=f(E)
\end{aligned}
$$

Above functions are be " $n$ " interval and other factors are be constant in each function[4].

\section{Lagrangian Polynomial}

Let $\mathrm{y}=\mathrm{f}(\mathrm{x})$ be a function which assume " $\mathrm{n}$ " values $\left(\mathrm{x}_{1}, \mathrm{y}_{1}\right),\left(\mathrm{x}_{2}, \mathrm{y}_{2}\right), \ldots$, $\left(\mathrm{x}_{3}, \mathrm{y}_{3}\right), \ldots,\left(\mathrm{x}_{\mathrm{n}}, \mathrm{y}_{\mathrm{n}}\right)$ corresponding to the argument $\mathrm{x}_{1}, \mathrm{x}_{2}, \mathrm{x}_{3}, \ldots, \mathrm{x}_{\mathrm{n}}$ not necessarily eqully spaced [5]:

$$
Y(x)=\sum_{i=1}^{n} Y_{i} \prod_{\substack{j=1 \\ j \neq i}}^{n} \frac{\left(x-x_{j}\right)}{\left(x_{i}-x_{j}\right)}
$$

This is called Lagrangian polynomial [6].

\section{Effect of Concentration of Enzyme}

Assuming a sufficient concentration of substrate is available, increasing Enzyme concentration will increase the enzymatic reaction rate [7].

\subsection{Formula for obtaining intermediate values}

Let $\mathrm{V}=\mathrm{f}(\mathrm{E})$ be a function defined by " $\mathrm{n}$ " points $\left(\mathrm{E}_{1}, \mathrm{~V}_{1}\right),\left(\mathrm{E}_{2}, \mathrm{~V}_{2}\right), \ldots,\left(\mathrm{E}_{\mathrm{n}}, \mathrm{V}_{\mathrm{n}}\right)$. Where " $V$ " is the rate of Enzymatic reaction and " $E$ " is the concentration of Enzyme. And other factors are to be constant. Substituting these values in the equation (1), we got:

$$
\mathrm{V}(\mathrm{E})=\sum_{i=1}^{n} \mathrm{~V}_{\substack{j=1 \\ j \neq i}} \prod_{\substack{j \\ j \neq i}} \frac{\left(\mathrm{E}-\mathrm{E}_{j}\right)}{\left(\mathrm{E}_{i}\right)}
$$

\section{Effect of Concentration of Substrate}

At the constant enzyme concentration and other factor, the concentration of substrate is the limiting factor, as the substrate concentration increases, the 
Enzyme reaction rate increases. However, at very high substrate concentration, the Enzyme becomes saturated with substrate and a higher concentration of substrate does not increase the reaction rate [7].

\subsection{Formula for obtaining intermediate values}

Let $\mathrm{V}=\mathrm{f}(\mathrm{S})$ be a function defined by " $\mathrm{n}$ " points $\left(\mathrm{S}_{1}, \mathrm{~V}_{1}\right),\left(\mathrm{S}_{2}, \mathrm{~V}_{2}\right), \ldots,\left(\mathrm{S}_{\mathrm{n}}, \mathrm{V}_{\mathrm{n}}\right)$. Where "V" is the rate of reaction and " $\mathrm{S}$ " is the concentration of substrate. And other factors are to be constant. Substituting these values in the equation (1), we got:

$$
\mathrm{V}(\mathrm{S})=\sum_{i=1}^{n} \mathrm{~V}_{i} \prod_{\substack{j=1 \\ j \neq i}}^{n} \frac{\left(\mathrm{S}-\mathrm{S}_{j}\right)}{\left(\mathrm{S}_{i}-\mathrm{S}_{j}\right)}
$$

\section{Effect of Temperature}

The rise in Temperature accelerates an Enzyme reaction but at the same time causes inactivation of the protein. At certain Temperature known as the optimum Temperature the activity is maximum $[3,8]$.

\subsection{Formula for obtaining intermediate values}

Let $\mathrm{V}=\mathrm{f}(\mathrm{T})$ be a function defined by " $\mathrm{n}$ " points $\left(\mathrm{T}_{1}, \mathrm{~V}_{1}\right),\left(\mathrm{T}_{2}, \mathrm{~V}_{2}\right), \ldots,\left(\mathrm{T}_{\mathrm{n}}, \mathrm{V}_{\mathrm{n}}\right)$. Where "V" is the rate of reaction and " $\mathrm{T}$ " is the Temperature of reaction. And other factors are to be constant. Substituting these values in the equation (1), we got:

$$
\mathrm{V}(\mathrm{T})=\sum_{i=1}^{n} \mathrm{~V}_{i} \prod_{\substack{j=1 \\ j \neq i}}^{n} \frac{\left(\mathrm{T}-\mathrm{T}_{j}\right)}{\left(\mathrm{T}_{i}-\mathrm{T}_{j}\right)}
$$

\section{Conclusion}

We obtained intermediate values of Enzymatic reaction rate using formulas in the interval. When the value of Enzyme concentration (E) is increased in interval then the value of the Rate of Enzymatic Reaction (V) is increased in interval. Where " $n$ " is optimum limit of Enzyme concentration (E). When the value of concentration of substrate $(\mathrm{S})$ is increased in interval then the value of the Rate of Enzymatic Reaction (V) is increased in interval. Where " $n$ " is optimum limit of 
substrate concentration (S). when the value of Temperature $(T)$ is increased in interval then the value of the Rate of Enzymatic Reaction (V) is increased in interval. Where " $n$ " is optimum limit of Temperature (T).

\section{Acknowledgments}

I would like to gratefully and sincerely thank Sayyad Maksud Ali, Mansur Ali, Abdul Ali and Isahaq Uddin Sheikh for their continuous support all time. My sincere thank due to Soumya V G. My thank is also due to Munavvar Ali.

\section{References}

[1] Wikipedia, the free encyclopedia: http://en.wikipedia.org/wiki/Lagrange_polynomial Accessed Jun 22, 2012.

[2] "B.D. singh", "Biotechnology", second Edition(2007), kalyani publishers, new delhi.

[3] "A.C. Deb", "Fundamental of biochemistry", Eight edition(2002), new central book agency, kolkata-9.

[4] "Nizam Uddin", "Interpolate the Rate of Enzymatic Reaction: Temperature, Substrate Concentration and Enzyme Concentration based Formulas using Newton's Method" , "International Journal of Research in Biochemistry and Biophysics", Volume 2, Issue 2, 2012.

[5] "S.R. Gupta", "A text book of computer oriented numerical methods", First Edition(2002), Nakoda publisher \& printers, Indore-2.

[6] "Bhagat V", "computer oriented numerical methods", First Edition (200405), kamal prakashan, Indore-2

[7] The Community College of Baltimore County : student.ccbcmd.edu/ gkaiser/biotutorials/proteins/enzyme.html, Accessed Jun 22, 2012.

[8] "Singh R.N.", "Biology”, yugbodh publication, Raipur. 